\title{
LEMINSKI EM JOGO: NOMEAÇÕES E DESLOCAMENTOS
}

\section{Elisa Tonon*}

\begin{abstract}
Resumo: Esse artigo descreve algumas cenas de nomeação de Paulo Leminski, com o intuito de analisar como se dá a inscrição do nome próprio. Para tanto destaco nomeações realizadas nos poemas e textos escritos por Leminski; algumas feitas pela crítica; e dedico especial atenção à realizada pelo vídeo Meu nome é Paulo Leminski, de Cézar Migliorin. A proposta é considerar essas nomeações como trabalhos de linguagem que têm como efeito devolver intensidade ou não, encenando a consagração ou a rasura do nome (e do corpus a ele relacionado). Para isso, interessa aqui suspender a separação entre as instâncias da crítica, da literatura, do cinema e do vídeo, para considerá-las como práticas de escrita em sentido amplo, como propôs Roland Barthes.
\end{abstract}

Palavras-chave: Poesia. Video. Escritura. Jogo. Linguagem.

\begin{abstract}
Teimar quer dizer afirmar o Irredutível da literatura; o que, nela, resiste e sobrevive aos discursos tipificados que a cercam: as filosofias, as ciências, as psicologias; agir como se ela fosse incomparável e imortal. Um escritor - entendo por escritor não o mantenedor de uma função ou o servidor de uma arte, mas o sujeito de uma prática - deve ter a teimosia do espia que se encontra na encruzilhada de todos os outros discursos, em posição trivial com relação à pureza das doutrinas (trivialis é o atributo etimológico da prostituta que espera na intersecção de três caminhos). Teimar quer dizer, em suma, manter ao revés e contra tudo a força de uma deriva e de uma espera. E é precisamente porque ela teima, que a escritura é levada a deslocar-se. Pois o poder se apossa do gozo de escrever como se apossa de todo gozo, para manipulá-lo e fazer dele um produto gregário, não perverso, do mesmo modo que ele se apodera do produto genético do gozo de amor para dele fazer, em seu proveito, soldados e militantes. Deslocar-se pode pois querer dizer: transportar-se para onde não se é esperado, ou ainda e mais radicalmente, abjurar o que se escreveu (mas não, forçosamente, o que se pensou), quando o poder gregário o utiliza e serviliza.
\end{abstract}

Roland Barthes. Aula.

A leitura que desenvolvo aqui ${ }^{1}$ tem como ponto de partida as perguntas feitas por Jacques Derrida no verbete que escreveu sobre Mallarmé, com ele pergunto: existe um lugar, um posto, para Leminski em uma história da literatura? Ou então: seu texto tem lugar, seu lugar, em algum quadro da literatura brasileira? Em um quadro? Da literatura? Brasileira?

Se junto com a escrita se dá o processo de invenção de uma figura de autor, como nos mostra o crítico argentino Julio Premat no livro Héroes sin atributos, e de um nome de autor, como Derrida enfatiza com suas perguntas, a configuração do autor Paulo Leminski ocorre com as intervenções realizadas nos textos e nas imagens (fotografias e vídeos realizados por ele) em que uma performatização acontece, e se estende também pelas leituras e nomeações que o poeta realiza e recebe. Nesse acúmulo de textos e de epítetos, se inserem e reafirmam imagens e associações determinadas, ou seja, com a

\footnotetext{
* Doutora em Teoria Literária pela Universidade Federal de Santa Catarina - UFSC. Professora de Literatura no Instituto Federal de Santa Catarina - IFSC. E-mail: elisahtonon@hotmail.com.

${ }^{1}$ Esse trabalho é ampliação de um subcapítulo da tese "Vida coisa pra ser dita: envio, metamorfose e (auto)biografia em Paulo Leminski”, defendida em 2014 (UFSC).
} 
proliferação do arquivo proliferam também os modos de inscrever ou de trazer à cena Paulo Leminski.

De início, necessário lembrar as inserções do nome próprio feitas em seus textos e que constituem modos de exposição, como a frase que aparece no depoimento de 1979 concedido à revista Escrita: "Detesto poesia dita profunda. Estou cagando e andando para a psicologia. Não tenho psique. Sou uma besta dos pinheirais." (BONVICINO, 1999, p. 194), repetida no vídeo "Ervilha da fantasia" de1982, ou no conhecido poema (espécie de autorretrato):

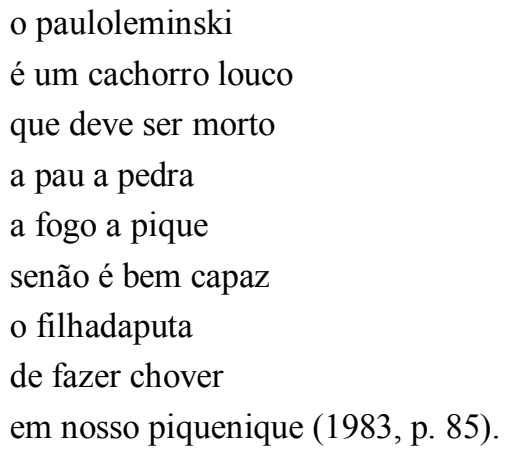

Ou em tom também brincalhão porém mais solene, no poema:

com quantos paulos

paulos paulos paulos

quantos paulos são precisos

para fazer um são paulo?

idades idades idades

quanto dá uma alma

dividida por duas cidades? (1991, p. 32).

Ou ainda em carta a Régis Bonvicino:

somos os últimos concretistas e os primeiros não sei o que lá

somos centauros

metade decadentes alexandrinos bizantinos

e metade bandeirantes pioneiros Marcopolos (BONVICINO, 1999, p. 194).

A crítica também intervém na construção desse nome ou na configuração do mito, especialmente quando recorreu diversas vezes a epítetos duplos e caracterizações inusitadas para apresentar leituras de Leminski, tirando partido de um procedimento largamente utilizado pelo poeta em seus textos e mesmo nos títulos de seus livros. Exemplo disso é o texto de Leyla Perrone-Moisés intitulado "Leminski, o samurai 
malandro"; permeado pelos epítetos duplos, nele o poeta é descrito como "samurai em seus caprichos e malandro em seus relaxos", rápido no "golpe" e na "ginga", "beatnik caboclo", "malandro zen", e já no trecho final do texto, lemos

\begin{abstract}
Leminski era transcultural: polonês, caboclo e 'japonês', malandro e samurai, provinciano e internacional. Jogava na várzea e falava latim. Eclético e autodidata, era o mais brasileiro dos poetas [...]. Leminski era intratável. Amor e raiva em fúrias equivalentes, uma força que podia dar em abraço ou em murro. O que garante a sua poesia aquele calor dentro do rigor, palavras habitadas por um corpo (LEMINSKI, 2013, p. 403).
\end{abstract}

Ou no texto de Haroldo de Campos sobre Caprichos \& relaxos, que se refere ao poeta como "Rimbaud curitibano com físico de judoca, escandindo versos homéricos, como se fosse um discípulo zen de Bashô, o Senhor Bananeira, recém-egresso do Templo Neopitagórico do simbolista filelênico Dario Vellozo." E o de Caetano Veloso, para o mesmo livro, que nos diz "Leminski tem um clima/mistura de concretismo com beatnik".

Também na biografia escrita por Toninho Vaz e publicada em 2001 o procedimento está presente com título $O$ bandido que sabia latim. Na apresentação do livro, Vaz explica, mencionando um diálogo com Alice Ruiz em fins de 1998, que "com a morte do poeta, dez anos antes, o culto à sua obra e personalidade - principalmente em Curitiba, onde foi transformado em mito pelas novas gerações - só fez aumentar o interesse e a curiosidade por sua vida - vale dizer, tão extraordinária quanto sua obra" (VAZ, 2001, p. 13).

Percebe-se como falar sobre Leminski é, inevitavelmente, falar de uma contradição, de algo imprevisto, que excede a descrição convencional ou qualquer classificação, e que requer sempre o olhar e a ênfase para os dados biográficos, a caracterização dos gestos (o físico, o tom de voz, o jeito de vestir). Não por acaso, o excesso é frequentemente expresso pela menção às suas referências de leitura, em combinações pouco previsíveis (como faz o texto de Haroldo de Campos) ${ }^{2}$.

Portanto, recorrer a esse procedimento é um modo de assinalar o excesso ou a excepcionalidade do poeta, e, com isso, ele opera no sentido da auratização, da apresentação de Leminski como uma espécie de herói mítico, ou santo, como já apontou Flora Süssekind em "Hagiografias" (2007).

A operação realizada pela crítica nesses exemplos parece gerar um efeito diferente do obtido nos textos em que o poeta insere seu nome ou seus epítetos, já que como visto, neles a (auto)referência vem carregada de sarcasmo, ironia e, portanto, de rasura, de deslocamento.

\footnotetext{
2 Paula Renata Melo Moreira em sua tese destaca esse aspecto e cita breve descrição do poeta que acompanha texto publicado na Revista Isto é: "Paulo Leminsky (sic), 37 anos, paranaense: se define como um tatu. Poeta amigo dos concretistas, Catatau é seu livro mais importante. Embora com formação musical de canto gregoriano, fez parceria com Paulinho Boca de Cantor (Aleu [sic]) e Caetano (Verdura). Foi seminarista dos monges beneditinos e atualmente trabalha numa agência de publicidade (Isto é, 9/6/1982)" (2011, p. 75).
} 
Efeito ainda diverso vemos no filme "Meu nome é Paulo Leminski" (2004) de Cezar Migliorin ${ }^{3}$. Em cerca de cinco minutos, o vídeo nos apresenta cenas da intimidade doméstica, em preto e branco. O pai, que controla a câmera, filma o filho Diego de três anos de idade sentado no chão do quarto, recitando o poema "Poesia 1970" de Paulo Leminski. Enquanto o menino repete os versos ditados pelo pai, ele brinca com uma almofada, coloca-a sobre a cabeça, e apesar de o poema ser breve, a segunda repetição já é suficiente para provocar a impaciência. O filho, então, começa a dizer seu próprio poema, enquanto manipula um brinquedo de montar, e o texto vai se transformando proporcionalmente à irritação crescente da criança; a voz do pai ainda segue ditando e repetindo o poema, incessantemente, até que o menino choroso grita: "Cala boca! Eu não quero mais fazer! Ô pai eu não quero! Esse filme tá ruim. Droga. Tchau" e sai de foco, deixando um espaço vazio, até que o olhar da câmera se move para outra criança, a garotinha Elisa, que brincava no espaço ao lado do irmão, concentrada e distraída, sem se afetar com o projeto do pai ou com os arroubos do irmão; Elisa olha para a câmera e volta a brincar. Ouvimos o choro e o balbucio do menino ao longe, até que ele retorna ao quarto, desliga a luz, passa em frente à câmera, muda a direção dela, sobe na janela, pendura-se na grade, e agora com a voz calma dá o comando "para de filmar, pai", com o qual a câmera é desligada.

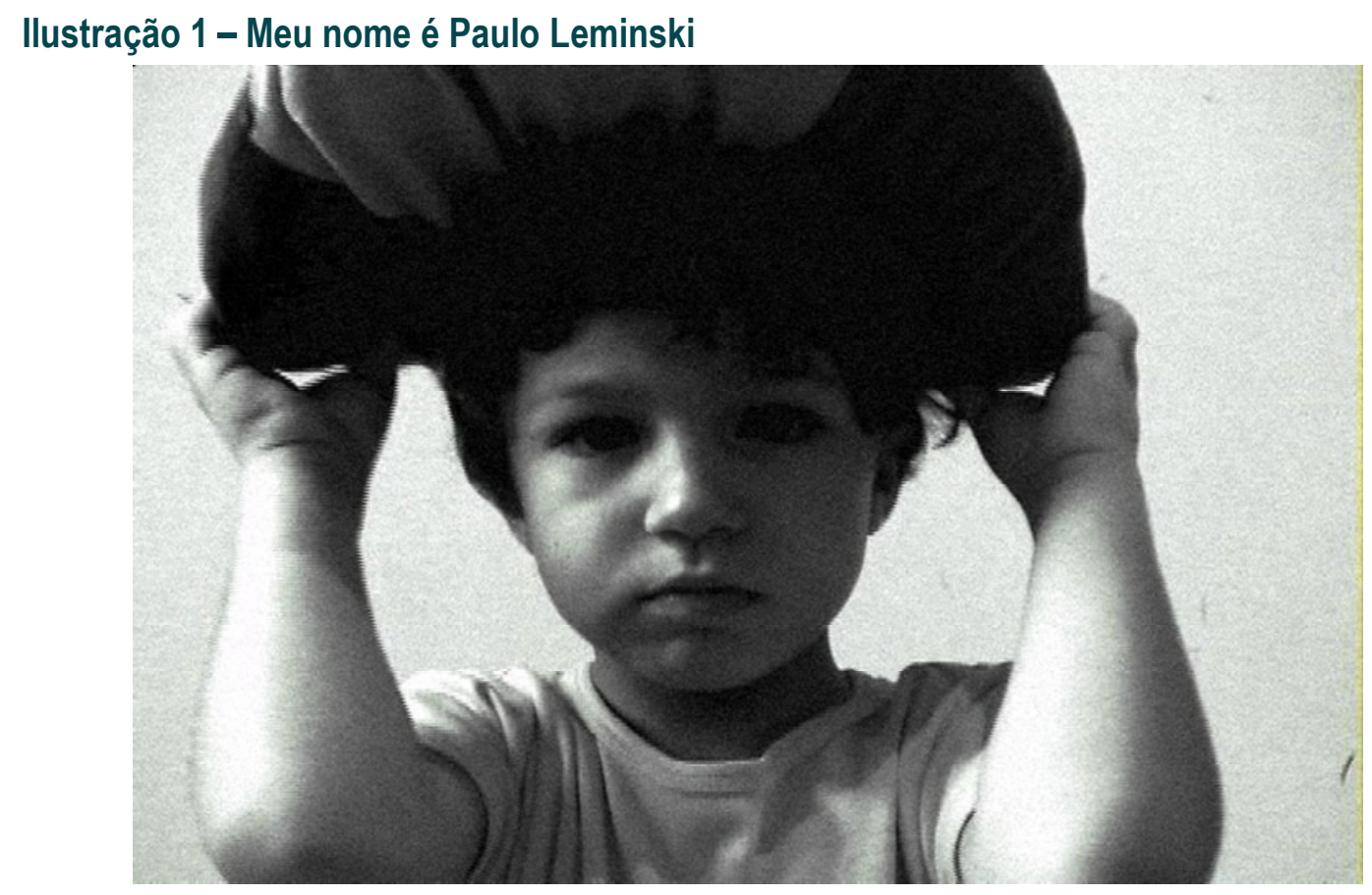

Neste vídeo "caseiro" temos um plano-sequência apresentando algo da ordem da intimidade, do privado: a casa, os brinquedos, a voz do pai e a imagem dos filhos. Sobre as relações entre cinema e vídeo, Ivana Bentes tece as seguintes considerações:

\footnotetext{
${ }^{3}$ Agradeço a Manoel Ricardo de Lima a referência e acesso ao vídeo.
} 
A câmera de vídeo, ao fazer coincidir o real e sua encenação, ao criar um continuum, uma duração, um registro sem interrupção, reencontrava o frescor da presença e do 'ao vivo'. A câmera tornada personagem, aberta ao real, ao acaso e ao mundo, marca o estilo do direto (ele mesmo influenciado pela reportagem de TV) e será um dos procedimentos marcantes do vídeo (2003, p. 113).

O princípio do "ao vivo", que foi logo incorporado pela televisão a partir dos anos 1970 até se tornar regra de estilo, tem como característica "forçar" a realidade a acontecer, constituindo uma "retórica da espontaneidade", conforme Bentes. Os procedimentos utilizados por Migliorin, portanto, tiram proveito do efeito de flagrante da vida doméstica, porém o que o vídeo oferece ao espectador não parece ser a posição cômoda do voyeur.

Fica claro que há uma intencionalidade que conduz a cena, há comando e um papel a ser desempenhado e esses aspectos estão organizados em torno do texto. $\mathrm{O}$ poema de Leminski, ditado pelo pai e repetido por Diego, é o dispositivo que ativa o acontecimento. Mais especificamente, é um dispositivo de linguagem, ou um jogo de linguagem ${ }^{4}$, que move a cena (e a subjetividade que vemos) em substituição ao roteiro ou à captação de um suposto real ao acaso.

Nesse jogo, o pai que tem a câmera provoca a irritação e rebeldia do filho, que quer outra coisa - quer brincar, jogar o seu jogo, quer dizer suas palavras, quer encerrar o filme - e passa a deturpar, rasurar o que o pai the obriga a dizer. É justamente da imposição do pai que surge a resistência do filho, e com ela um poema imprevisto, e já não é possível definir quem efetivamente conduz ou cria a cena a que assistimos.

Nos créditos do vídeo, somos informados de que ele foi livremente inspirado no vídeo "Imprescindíveis" de Carlos Magno, também um vídeo com cinco minutos de duração, em que o pai filma o filho Bruno, a quem pede que repita o nome de líderes revolucionários (Marighela, Zapata, Comandante Marcos); no entanto o filho diz apenas nomes de heróis da televisão (Jaspion, Batman, Robin). O trabalho de Magno é uma referência muito cara para Migliorin, que analisa os vídeos onde Magno filma seus filhos, identificando no uso dessa "câmera íntima" um jogo de improvisação: "É desta dupla paixão que os filmes são feitos; invenção do mundo privado, de um filho e de um pai e invenção de um mundo novo, que passa pelo privado" (2008, p. 98). O ato de filmar, portanto, é compreendido como uma escritura, uma relação com a linguagem. No entanto, nos filmes de Magno (além de "Imprescindíveis", "Kalashnikov" e "Anticristo") a montagem cumpre um papel especial, ela acumula uma série de fragmentos díspares, e por isso impede o efeito voyeur que os vídeos poderiam causar. Migliorin chama atenção também para a presença das legendas em inglês nestes filmes, outro recurso que insere a descontinuidade no universo privado:

\footnotetext{
${ }^{4}$ No artigo "O grau zero da subjetividade: documentários e jogos de linguagem" Pablo Gonçalo analisa a presença dos jogos de linguagem em alguns documentários, e investiga o conceito a partir de Wittgenstein, para quem os jogos de linguagem "flertam diretamente com a gramática, o contexto, os usos e os modos de ressignificação - para além, portanto, de regras específicas e estruturas estruturantes; os jogos de linguagem apostam no uso e na prática da gramática" (2011, p. 240).
} 
As legendas em inglês têm certamente o objetivo de permitir que o filme seja apresentado no exterior, destino frequente dos trabalhos em vídeo que se situam neste campo entre o documentário e a chamada videoarte ou vídeo de criação. Mas, não é apenas com o objetivo de comunicação que Magno faz essas legendas, elas não são simplesmente aplicadas à obra, mas passam a compor a visibilidade mesmo da obra e acabam por se confundir com as legendas em português [...]. As legendas acabam sendo limite e mediação para esta crueza da narrativa; não nos tornamos voyeurs da vida privada, pois ela está sempre mediada por aspectos técnicos ou por discursos que desarmonizam as imagens (2008, p. 103-104).

As legendas em inglês de "Meu nome é Paulo Leminski" têm funcionamento semelhante, explicitam o aspecto de escritura do vídeo ao ressaltar que a fala de Diego é texto, poema. No entanto, diferentemente de Magno que reforça a descontinuidade com a ênfase no corte e montagem de imagens, sons e textos diversos que atravessam a cena íntima, a opção de Migliorin pelo plano sequência confere unidade à narrativa, mas essa não é uma unidade pacífica ou harmônica. Ao colocar em cena um nome de autor, um poema, e com isso uma época, um contexto da cultura brasileira, sem contudo realizar um discurso referencial (ou reverencial), o que se desenrola é um jogo de linguagem que é também jogo de forças, pois ele acontece na relação entre pai e filho, entre a câmera e quem é filmado. As relações de poder estão ali não apenas registradas, mas são o motor da narrativa. A insistência do pai com a câmera e com o ditado incessante do texto provoca, irrita o filho, o faz passar do poema repetido à criação do seu poema da recusa, aos palavrões, aos xingamentos ao pai "burro, idiota, cagão", ao choro, à retirada, ao retorno, e ao comando final, o assertivo "para de filmar, pai".

O vídeo nos dá a ver a tensão e o atrito que permeiam as relações (com o pai/câmera) e também o que se inventa, o que se escreve com essa tensão, nessa tensão - as subjetividades em devir, no embate com a língua:

Todo um esforço ético e estético para dar conta do óbvio: o eu não fala, o eu não diz, ele é parte da linguagem e opera no seu interior. Dizer eu, nessa política da imagem, é uma forma de operar simultaneamente uma reapropriação da linguagem, uma saída de si. A relação pai e filho aqui é o que expõe a falta de estabilidade entre esses indivíduos e o modo como eles são o tempo todo confrontados com universos que demandam um recuo reflexivo em relação a si mesmos. Se separar de si e refazer um caminho na linguagem, com as imagens (idem, p. 16).

A relação com a literatura e com a tradição literária de uma época aparece também de maneira tensa, inoperante. Com a inserção do verso "Meu nome é Paulo Leminski" antes do poema, o texto se torna um texto de nomeação, assim como o vídeo, já que o novo verso lhe dá nome, portanto, poema e vídeo são transformados em um autorretrato - de Leminski, de Diego, de Cézar?

Mas é importante destacar que o gesto do pai ao dar voz ao filho, ocorre com o recurso ao nome de outro, à linguagem de outro, à presença do autor, que aparece deslocado, desautorizado. A nomeação coincide justamente com o ponto em que Diego rasura o poema e com ele o nome, "Paulo Leminski" passa a ser "bunda Leminski", "lapaxipapakiki", "bagundalagagun", num tatibitate infantil, choroso, que mimetiza o ritmo do poema e o abre a sua continuidade. 
As metamorfoses do nome e do texto acabam com a possibilidade estereotipada de uma performance exemplar do filho prodígio, um clássico; o que nos é oferecido, ao contrário, é ordem, violência, recusa, negação, invenção, brincadeira, lágrimas.

"Poesia 1970" é o poema em que Leminski se refere à geração sua contemporânea, aquela que foi chamada de poesia marginal, e nos fala de uma relação ambígua, de pertencimento e diferenciação ${ }^{5}$, com relação a ela.

Tudo o que eu faço

Alguém em mim que eu desprezo

Sempre acha o máximo

Mal rabisco,

Não dá mais pra mudar nada

Já é um clássico (1987, p. 97).

O poema retoma o aspecto espontâneo de certa escrita literária dos anos 70, e a espontaneidade aqui está ligada não somente ao tipo de escrita "expressiva", mas a uma recepção acolhedora e instantânea, que o torna imediatamente "clássico" ainda que desprezível.

O poema, portanto, nos traz o tema da consagração, frequente ao longo da poesia de Leminski, e é com ironia que a figura da obra prima retorna em alguns poemas. Ao mesmo tempo em que o fazer poético é algo heroico, vinculado a uma santidade, é também um "despropósito":

\section{Despropósito geral}

Esse estranho hábito, escrever obras primas. não me veio rápido. Custou-me rimas.

Umas, paguei caro, liras, vidas, preços máximos.

Umas, foi fácil.

Outras, nem falo.

Me lembro duma

que desfiz a socos.

Duas, em suma.

Bati mais um pouco.

Esse estranho abuso,

\footnotetext{
${ }^{5}$ A postura ambígua com relação à poesia marginal e aos seus contemporâneos é encontrada também no texto "O boom da poesia fácil", no qual Leminski vê como positivo o resgate da dimensão lúdica, o tom zombeteiro nessa poesia que é "contra a mistificação literária", porém critica a improvisação, o desleixo e o facilitário, que segundo ele "já cumpriram o seu papel histórico" e, portanto, são desnecessários. (LEMINSKI, 2011, p. 64.)
} 
adquiri, faz séculos.

Aos outros, as músicas.

Eu, senhor, sou todo ecos (1987, p. 43).

Aqui a escrita aparece como enfrentamento, duelo, algo caro, custoso, um dispêndio de vida, um abuso. A obra prima, portanto, seria mais uma "câmara de ecos", como quis Waly Salomão. Metamorfosear-se, tornar-se permeável, "todo ecos" é tarefa vital que a poesia realiza. Essa proposta não é diferente da constatação que encerra a biografia de Cruz e Sousa e que é, também, uma convocação, uma mirada lançada ao leitor: "Perfeição só existe na integração/ dissolução do sujeito no objeto. Na tradução do eu no outro. É por isso que você gostou tanto deste livro. Você, agora, sabe. Você, eu, sou Cruz e Sousa" (1983b, p. 37).

Assim como "Poesia 1970" encena as relações que atravessam a literatura e escrita, nos mostrando um embate com a linguagem no qual há um sujeito cindido, o filme de Migliorin problematiza o ato de filmar (e de assistir) o vídeo, evidenciando afetos e violências que permeiam essas atividades. O trabalho com o vídeo é também escritura, nele têm lugar o embate e a trapaça com a língua, como propôs Roland Barthes em sua Aula:

\begin{abstract}
Ao mesmo tempo teimar e deslocar-se, isso tem a ver, em suma, com um método de jogo. Assim não devemos espantar-nos se, no horizonte impossível da anarquia linguareira - ali onde a língua tenta escapar ao seu próprio poder, à sua própria servidão -, encontramos algo que se relaciona com o teatro. Para designar o impossível da língua, citei dois autores: Kierkgaard e Nietzsche. Entretanto, um e outro escreveram; mas foi, para um e outro, ao revés da própria identidade, no jogo, no risco desvairado do nome próprio: um, pelo recurso incessante da pseudonímia; o outro chegando, no fim de sua vida de escritura, como mostrou Klossovski, aos limites do histrionismo. Pode-se dizer que a terceira força da literatura, sua força propriamente semiótica, consiste em jogar com os signos em vez de destruí-los, em colocá-los numa maquinaria de linguagem cujos breques e travas de segurança arrebentaram, em suma, em instituir no próprio seio da linguagem servil uma verdadeira heteronímia das coisas (2009, p. 27-28).
\end{abstract}

O modo como Leminski é colocado em cena por Migliorin devolve o nome a um campo aberto, o coloca em jogo, assim como os vários discursos que ali estão, não tematizados, representados ou ficcionalizados, mas friccionados - literatura, poesia, cinema, consagração, autoria, nomeação, pai, filhos, vida cotidiana, reality shows - sem que o vídeo seja um discurso sobre qualquer uma dessas coisas, mas é um discurso com, e por isso diz mais.

REFERÊNCIAS

ARFUCH, Leonor. O espaço biográfico: dilemas da subjetividade contemporânea. Tradução de Paloma Vidal. Rio de Janeiro, EdUERJ, 2010.

BARTHES, Roland. Aula. Tradução de Leyla Perrone-Moisés. 14a edição. São Paulo, Cultrix, 2009.

BENTES, Ivana. "Vídeo e cinema: rupturas, reações e hibridismos", in: MACHADO, Arlindo (Org.).

Made in Brasil: três décadas do vídeo brasileiro. Itaú Cultural, São Paulo, 2003. p.113-132. 
BONVICINO, Régis (Org.); LEMINSKI, Paulo. Envie meu dicionário: cartas e alguma crítica. São Paulo, Ed. 34, 1999.

CAMPOS, Haroldo de. O arco-íris branco. Ensaios de literatura e cultura. Rio de Janeiro: Imago, 1997. "Uma leminskíada barrocodélica". In: Caderno Letras, Folha de S. Paulo, 2 set. 1989.

COMOLLI, Jean Louis. "Sob o risco do real". In: Catálogo Forumdoc.bh.2001. Belo Horizonte: Filmes de Quintal, 2001.

DE MAN, Paul. Autobiografia como des-figuração. Tradução de Joca Wolff. Sopro n.71. Maio de 2012.

DERRIDA, Jacques. "Mallarmé”. Tableau de la literature française, vol. III, Paris: Gallimar, 1974, p.368-379. Versão em espanhol disponível em: http://www.jacquesderrida.com.ar/textos/mallarme.htm

Mal de arquivo: uma impressão freudiana. Tradução de Claudia de Moraes Rego. Rio de Janeiro: Relume Dumará, 2001.

EDUARDO, Cléber. "O pai com a câmera". Revista Cinética. Disponível em: http://revistacinetica.com.br/pertodecasa.htm

GUIMARÃES, César; GUIMARÃES, Victor. "Da política no documentário às políticas do documentário: notas para uma perspectiva de análise”. Revista Galáxia, São Paulo, n. 22, p. 77-88, dez. 2011.

GONÇALO, Pablo. "O grau zero da subjetividade: jogos de linguagem e documentários". Crítica Cultural, Palhoça, SC, v. 6, n. 1, p. 233-249, jan./jul. 2011. ISSN 1980-6493

LEMINSKI, Paulo. Caprichos \& relaxos. São Paulo, Brasiliense, 1983.

Cruz e Sousa - o negro branco. São Paulo, Brasiliense, 1983 b.

Distraídos venceremos. São Paulo, Brasiliense, 1987.

La vie en close. São Paulo, Brasiliense, 1991.

Toda poesia. São Paulo, Companhia das Letras, 2013.

MIGLIORIN, Cesar (Org). Ensaios no real: o documentário brasileiro hoje. Rio de Janeiro: Azougue, 2010.

Eu sou aquele que está de saída: dispositivo, experiência e biopolítica no documentário brasileiro contemporâneo. [Tese] Universidade Federal do Rio de Janeiro, 2008.

MOREIRA, Paula Renata Melo. Ensaísmo de Paulo Leminski [manuscrito]: panorama de um pensamento movente. [Tese] Universidade Federal de Minas Gerais, 2011.

PEDROSA, Célia. "Paulo Leminski: sinais de vida e sobrevida". In: Alea, vol.8 n.1, Rio de Janeiro, Jan. 2006

PREMAT, Julio. Héroes sin atributos: figuras de autor en la literatura argentina. Buenos Aires, Fondo de Cultura Económica, 2009.

SUSSEKIND, Flora. "Hagiografias” In: Inimigo rumor, n. 20, São Paulo/Rio de Janeiro, CosacNaify/ 7Letras, 2007, p.29-65.

TONON, Elisa Helena. Vida coisa pra ser dita: envio, metamorfose e (auto)biografia em Paulo Leminski. [Tese]. Universidade Federal de Santa Catarina, 2014.

VAZ, Toninho. Paulo Leminski: o bandido que sabia latim. Editora Record, Rio de Janeiro, 2001.

OBRAS AUDIOVISUAIS

MAGNO, Carlos. Imprescindíveis, 2003.

Kalashnikov, 2005

Anticristo, 2006.

MIGLIORIN, Cesar. Meu nome é Paulo Leminski. 2004.

SCHUMANN, Werner. Ervilha da fantasia, 1982.

Recebido em 05/10/2015. Aprovado em 28/10/2015.

TONON, Elisa. Leminski em jogo: nomeações e deslocamentos. Crítica Cultural - Critic, Palhoça, SC, v. 10, n. 2, p. 223-232, jul./dez. 2015. 
Title: Leminski at stake: naming and displacements

Abstract: This article describes some situations of Paulo Leminski's nominations. The intention is to analyze how the inscription of the proper name is made. For that, I highlight the nominations realized in poems and other Leminski's texts; in critics' text; and I dedicate special attention to Cézar Migliorin video Meu nome é Paulo Leminski. The proposal is to consider these nominations as works of language that has as effect the return of intensity, or not, performing the consecration or the erasure of the name (and of the corpus related). The aim is to suspend the separation between the instances of criticism, literature, cinema and video, considering them as practices of writing in a large sense, as Roland Barthes' proposal.

Keywords: Poetry. Video. Writing. Game. Language Texto. 